Cronfa - Swansea University Open Access Repository

This is an author produced version of a paper published in :

Midwifery

Cronfa URL for this paper:

http://cronfa.swan.ac.uk/Record/cronfa18100

\title{
Paper:
}

Brown, A., Rance, J. \& Warren, L. (2015). Body image concerns during pregnancy are associated with a shorter breast feeding duration. Midwifery, 31(1), 80-89.

http://dx.doi.org/10.1016/j.midw.2014.06.003

This article is brought to you by Swansea University. Any person downloading material is agreeing to abide by the terms of the repository licence. Authors are personally responsible for adhering to publisher restrictions or conditions. When uploading content they are required to comply with their publisher agreement and the SHERPA RoMEO database to judge whether or not it is copyright safe to add this version of the paper to this repository. http://www.swansea.ac.uk/iss/researchsupport/cronfa-support/ 
1 This is the preprint version of the following article: Brown, A., Rance, J., \& Warren, L.

2 (2015). Body image concerns during pregnancy are associated with a shorter breast

3 feeding duration. Midwifery, 31(1), 80-89. It has been published in final form at

4 http://www.sciencedirect.com/science/article/pii/S0266613814001715

5

6

\section{Body image concerns during pregnancy are associated with a shorter breast feeding duration}

\section{Corresponding Author}

Dr. Amy Brown

College of Human and Health Sciences

Swansea University, UK

SA2 8PP

Email: a.e.brown@swansea.ac.uk

Brown, A., Rance, J., Warren, L.

Swansea University, UK. 


\section{Abstract}

Objective: Breastfeeding is affected by numerous psycho-social factors. Prenatal concerns such as embarrassment regarding public feeding and the impact of breastfeeding upon breast shape are known to lead to formula use. However, although work has explored the relationship between maternal weight and infant feeding, wider body image concerns have not been examined. The aim of the current study was to explore the association between maternal body image concerns during pregnancy upon intended and actual breastfeeding duration.

Design: A two stage self report questionnaire completed during pregnancy and at six months postpartum

Setting: Mothers were recruited from local mother and infant groups, nurseries and online mother and infant forums.

Participants: One hundred and twenty eight pregnant women completed both stages

Measures: Phase One: Completion of a questionnaire exploring body image during pregnancy (concerns about stretch marks, weight gain and appearance) and planned breastfeeding duration during the second/third trimester of pregnancy (body image, weight, intended duration) followed by a second questionnaire measuring actual breastfeeding duration and breastfeeding experiences.

Findings: Factor analysis revealed three primary body image concerns; pregnancy body image, prospective postnatal body image and dieting during pregnancy. Higher concerns on all three factors were associated with both intended and actual shorter breastfeeding duration. Amongst mothers who stopped breastfeeding before six months, those with higher body image concerns were more likely to report stopping due to embarrassment or the perceived impact upon their breast shape. The relationship was not explained by maternal weight, although a higher residual weight gain at six months was associated with a shorter breastfeeding duration.

Conclusions and implications for practice: Mothers who are affected negatively by 
54 changes to their body during pregnancy may be less likely to plan to or initiate 55 breastfeeding potentially due to underlying issues such as embarrassment or 56 perceived impact of feeding upon their appearance. The findings are important to 57 those working with women during pregnancy and the postpartum period in 58 understanding the impact of body image upon intention and ability to initiate and 59 continue breastfeeding.

60

61 Key words: breastfeeding; body image; weight gain; attitudes; public feeding 
63

- Body image during pregnancy predicts both intended and actual

66 breastfeeding duration; higher body image concerns are associated with

67 formula use

- This relationship is not explained by weight alone, although residual higher weight gain at six months postpartum predicts a shorter breastfeeding duration

- Body image concerns are associated with stopping breastfeeding due to embarrassment and concerns about public feeding

- Perceptions about breastfeeding and its impact on appearance affect breastfeeding duration 
The World Health Organisation recommends exclusive breastfeeding for the first six months postpartum (WHO 2003). However, levels of breastfeeding in the UK are low; although $81 \%$ of women may initiate breastfeeding at birth, there is a sharp fall in continuation rates with only $55 \%$ feeding by six weeks postpartum (McAndrew, Thompson, Fellows, Large, Speed \& Renfrew, 2012).

83

Low breastfeeding rates can be explained by physical problems (such as pain, difficulty latching the infant on and exhaustion) but are also heavily driven by social and psychological factors. Mothers who lack social and professional support, feel they have little knowledge and confidence and are pressurized by others to stop breastfeeding are all more likely to use formula (Li et al, 2009; Thulier \& Mercer, 2008; Brown, Raynor \& Lee, 2011).

How a woman feels about her body has also been associated with breastfeeding. Women who feel embarrassed at breastfeeding in front of others or in public or who dislike the changes they believe breastfeeding may bring to their breasts are less likely to initiate or continue breastfeeding (Haughton, Gregorio \& Perez-Escamilla, 2010; Alexander, Dowling \& Furman, 2010; Wambach \& Cohen, 2009; Dyson, Green, Renfrew, McMillan \& Woolridge, 2010). Additionally, issues with seeing the breast as sexual rather than something to feed an infant or wanting to reclaim their body for themselves after pregnancy can impede breastfeeding (Drummond \& Willis, 2012; Kukla, 2006; Ogbuanu, Probst, Laditka, Liu, Baek \& Glover, 2009; Angell, 2006). Finally, breastfeeding has been associated with maternal weight. Mothers who are overweight or obese are less likely to initiate or continue breastfeeding ((Kitsantas \& Pawloski, 2009; Hilson, Rasmussen \& Kjolhede, 2004).

Weight gain (within the recommended range) and changes in body shape and appearance are an expected and healthy element of pregnancy. However, growing numbers of women appear to be concerned about their weight gain and appearance during pregnancy and may be at risk of developing a negative body image (Skouteris,

106 2011). Body image describes the cognitive, affective and behavioural aspects of 107 one's body (Cash, Fleming, Alindogan Steadman \& Whitehead, 2002). Negative body 
image is common during pregnancy (Skouteris, Carr, Wertheim, Paxton, \&

109 Duncombe, 2005) and extends to the postnatal period (Clark, Skouteris, Werthei,,

110 Paxton \& Milgrom, 2009; Duncombe, Wertheim, Skouteris, Paxton \& Kelly, 2008).

111 Women can be distressed by bodily changes in pregnancy, although some report

112 feeling liberated (Duncombe, Wertheim, Skouteris, Paxton, \& Kelly, 2008; Goodwin,

113 Astbury, \& McMekken, 2000). Pregnancy can trigger or intensify negative feelings

114 about the body or disordered eating (Conrad, Schablewski, Schilling, \& Liedtke, 2003;

115 Body image dissatisfaction during pregnancy can have a negative impact on both

116 mother and baby. It can be linked to unhealthy eating, dieting and purging

117 behaviours (Conti, Abraham, \& Taylor, 1998). In turn these behaviours increase the

118 risk of low infant birth weight and premature delivery (Kaiser, 2002; Olafsdottir, et

119 al., 2006) with higher levels of miscarriage (Franko, 2006) and caesarean delivery

120 (Franko et al., 2001) amongst pregnant women with disordered eating. Conversely,

121 poor body image can sometimes be associated with increased weight gain as the

122 woman binges or comfort eats (Devine, Bove, \& Olson, 2000; Mumford, Siega-Riz,

123 Herring, \& Evenson, 2008; Swann et al., 2009), a factor that has been associated with

124 infant macrosomia , caesarean section and later childhood overweight (Amorim,

125 Rossner, Neovius, Lourenco, \& Linne, 2007; Olson, 2008; Siega-Riz et al., 2009;

126 Olson, Strawderman, \& Dennison, 2009).

127 However, although the association between breastfeeding and maternal weight and

128 self image related to breastfeeding has been examined, there is little work, 129 particularly in the UK, exploring wider body image concerns during pregnancy such 130 as changing shape and weight gain and breastfeeding duration. Earlier work found 131 that pregnant women with increased concern about their body shape or weight 132 were less likely to intend to breastfeed (Barnes, Stein, Smith \& Pollock, 1997). 133 Similarly, a small qualitative study $(n=38)$ found that body shape concerns were 134 associated with intention to formula feed (Foster et al., 1996). More recently, in 135 Taiwan, pregnant women who rated their pre-pregnancy body image more positively 136 were more likely to plan to breastfeed. Finally, research has suggested that women 137 with anorexia are less likely to breastfeed (Larsson \& Andersson-Ellstrom, 2003; 138 Torgersen, Ystrom \& Haugen, 2010). 
140 The aim of the current study was to explore body image concerns in first time

141 pregnant women and examine their association with later breastfeeding initiation 142 and duration.

\section{Methodology}

\section{Participants}

146 Primiparous pregnant women who were in the second or third trimester of 147 pregnancy $(13-42$ weeks) took part in the study. Participants provided demographic 148 background (age, education, marital status, occupation).

150 All participants gave informed consent prior to inclusion in the study. Ethics approval 151 was granted by a Department of Psychology Research Ethics Committee. All aspects 152 of this study have been performed in accordance with the ethical standards set out 153 in the 1964 Declaration of Helsinki.

155 Participants were recruited through local antenatal classes / mother and baby 156 groups / community centers who encouraged pregnant women to attend and 157 through online pregnancy and mother and baby forums. Women could either 158 complete the questionnaire via a paper copy (used at face to face groups) or online 159 via an online questionnaire designed and hosted using SurveyMonkey.

\section{Questionnaire}

162 Participants completed two questionnaires. The first, in phase one during pregnancy, 163 examined their body image, pre pregnancy weight and height and intended mode of 164 infant feeding at birth and if relevant intended breastfeeding duration. A body image 165 questionnaire was constructed specifically for the study (Table one). Although 166 numerous validated body image questionnaires exist (e.g. The Body Esteem Scale 167 [Franzoi \& Shields, 1984], the Body Shape Questionnaire [Cooper, Taylor, Cooper\& 168 Fairbum, 1987], body self relations questionnaire [Brown, Cash \& Mikulka, 1990]) 
169 these have not been validated for use in pregnancy. Questions have been raised

170 over their suitability and validity at this time (Fuller-Tyszkiewicz, Skouteris, Watson \&

171 Hill, 2012). Furthermore, the study wished to examine specific body image concerns

172 related to pregnancy e.g. weight gain, stretch marks, concerns about appearance of

173 body postnatally rather than more generic concerns. Items were based on current

174 literature examining body image during pregnancy (e.g Skouteris et al, 2005; Clark et

175 al, 2009; Duncombe et al 2008) and discussion with mothers regarding body issues

176 that were associated with breastfeeding [Author A previous work]

178 In phase two, the second questionnaire was completed at six months postpartum 179 and examined mode of infant feeding at birth, any breastfeeding duration and if 180 relevant, reasons for breastfeeding cessation. Infants who were born prematurely, 181 who were low birth weight or who had significant health difficulties were excluded 182 from the sample. Participants also provided mode of delivery (caesarean / vaginal 183 birth). The items for breastfeeding cessation questionnaire was based on author A's 184 previous work (add ref after review). Items were based on factors known to affect 185 breastfeeding cessation in the current literature and previous published work 186 (Thulier \& Mercer, 2008; Li et al, 2009).

188 Mothers provided height and pre pregnancy BMI at phase one and current weight 189 (postnatal weight) at phase two (around 6 months postpartum). Weight and weight 190 change were not the primary measures of the study but were collected and 191 computed to explore whether body image itself, rather than weight was indicative of 192 breastfeeding duration. Although the two are correlated, it is possible to have poor 193 body image at a healthy weight. Moreover, body image is a wider concept than 194 weight alone, particularly during pregnancy where changes to breast shape, skin 195 elasticity and skin (e.g. stretch marks) are common.

\section{Data collection}

198 In phase one, for the face-to-face groups, permission was initially sought from the 199 group leader. The group leader distributed the questionnaire to mothers who 200 returned it to the group in a sealed envelope. For the online version of the 
questionnaire permission was sought from the host of various online parenting groups (e.g. www.mumsnet.com; www.bounty.com). Details of the questionnaire were then posted online with a link to the online version of the questionnaire. Both questionnaires included a participant information sheet and debrief with details of how to contact the researcher for further details or professional bodies if they had any concerns regarding pregnancy or infant care. Participants gave consent for phase

In phase two participants were either emailed a link to the follow up questionnaire or sent a paper version in the post dependent on indicated preference at phase one.

\section{Data Analysis}

213 Data was analysed using SPSS version 16.

215 Three weight measures were computed; pre pregnant BMI, postnatal BMI and 216 weight change. Pre pregnant BMI was used to explore the main associations with 217 body image as participants were pregnant at the time of completing the body image 218 questionnaire. Weight change during pregnancy was also used as it was considered a 219 potential measure of how much weight participants were gaining during pregnancy.

220 Postnatal BMI was collected to use as a covariate in the analyses as postnatal BMI is 221 associated with breastfeeding duration (as well as to compute weight gain). 222 Maternal height and pre pregnant / postnatal weight were used to compute pre 223 pregnant /postnatal BMI. Maternal postnatal weight and pre pregnant weight was used to compute weight difference at six months postpartum (e.g. weight gain or loss from pre pregnant weight).

227 For the items related to body image, exploratory factor analysis was conducted to determine items groupings. Using SPSS, a principal components factor analysis using

229 varimax rotation was performed, retaining factors with eigenvalues over 1. A 230 threshold of 0.5 was used to determine which variables should be retained. Further 231 analyses performed on split samples of the data for confirmation found similar 232 structures. The factor scores computed were saved as regression scores and used for 
233 the data analysis (Tabachnik \& Fidell, 2006). Cronbach's alpha was computed for

234 each factor to examine internal consistency of the factors produced.

236 Although the items for breastfeeding cessation questionnaire had been used in 237 previous research, exploratory factor analysis was used to group items. This ensured 238 greater reliability of item grouping. The method used was as above. Factors and item 239 groupings reflected previous research. Cronbach's alpha was computed for each 240 factor to check internal validity.

242 In addition, although the regression scores were used in the main analyses, for 243 clearer understanding of the descriptive data, factor scores were computed for each 244 of the three body image variables. The mean score for items loading onto each variable was computed for each participant. Likert scales were converted to

246 numbers from one for strongly disagree through to five for strongly agree and mean 247 score calculated for each factor.

MANCOVA were then used to examine differences in body image scales for women who intended to breast or formula feed at birth and postnatally for feeding method at birth (breast / formula) and any breastfeeding at two, six, twelve and twenty six weeks. Pearson $r$ correlations were used to explore associations between body

253 image and reasons for breastfeeding cessation. Maternal age, education, marital 254 status and occupation were controlled for alongside maternal BMI and birth mode 255 [vaginal/ caesarean].

\section{Results}

258 One hundred and twenty eight mothers completed both phases of the 259 questionnaire. The mean age of participants was 29.34 [SD: 5.52] (range 18 - 40). 260 Mean number of years in education was 13.03 [SD: 2.28]. Seventy two (58.2\%) were 261 in their second trimester and fifty one (39.8\%) in their third trimester. Gestation 262 ranged from 13 to 40 weeks with a mean stage of 24.20 weeks (SD: 8.97). Further details of the sample can be found in table 3 . 
265 Both planned (Pearson's $r=.167, p=.030$ ) and actual breastfeeding duration

266 (Pearson's $r=.210, p=.009$ ) were significantly associated with maternal age.

267 Moreover, the more years experience in education a mother had, the longer she 268 planned (Pearson's $r=.155, p=.040$ ) and did breastfeed (Pearson's $r=.207, p=$ $269.009)$.

271 No significant difference occurred in any of the body image scales for mothers in 272 trimester two or three in phase one.

274 No significant difference occurred in planned or actual breastfeeding duration, 275 maternal pre or postnatal weight, body image or maternal age and education 276 between mothers recruited online or face to face.

\section{Breastfeeding duration}

281 hundred and ten participants (85.9\%) planned to breastfeed whilst 18 (14.1\%) 282 planned to formula feed.

284 At six months postpartum, mothers reported feeding mode at birth and any 285 breastfeeding at two, six, twelve and twenty six weeks postpartum. One hundred 286 and two participants breastfed at birth (83.6\%) whilst 21 formula fed (16.4\%). 287 Breastfeeding duration can be found in table four. BMI and weight gain

290 Participants reported pre-pregnant height and weight from which pregnancy BMI 291 was computed. 12 were classed as underweight (9.4\%), 58 a normal weight (64.4\%) 292 and 31 overweight or obese (24.2\%). For postnatal BMI, only five mothers were 293 considered to have an underweight BMI (3.9\%), 77 a normal BMI (60.2\%) and 46 294 were overweight or obese (35.9\%). 
Participant weight change between pre pregnant and postnatal weight was also computed. Although the mean weight change was a gain of $1.3 \mathrm{~kg}$ (SD: 8.37 ), a wide

298 range of weight change was seen from a gain of $26 \mathrm{~kg}$ to a loss of $20 \mathrm{~kg} .53 .5 \%$ of participants were heavier at six months postpartum compared to their pre pregnant weight, $11.7 \%$ the same weight and $34.8 \%$ had lost weight. A significant association between pre pregnant weight and weight gain was found (Pearson's $r=-.227, p=$ .005). Mothers who had a lower weight before pregnancy were significantly heavier after pregnancy.

\section{Body Image}

Principal components factor analysis was performed on all items examining body image producing 3 factors and explaining $58.07 \%$ of the variance (Table 1 ). Factors were labeled 'pregnancy body image' (thoughts about pregnancy body), 'prospective postnatal body image' (concerns about how body would appear postnatally) and 'dieting during pregnancy' (active dieting during pregnancy). All items loaded highly onto a factor. One item 'I worry about stretch marks' loaded highly onto both pregnancy and postnatal factors and was included in each. Regression scores for each factor were computed and used for comparison. Cronbach's alpha was also computed for each factor, ranging from .729 to .782 and is also shown in Table 1.

Using the descriptive mean scores for each factor, body image was explored. Overall, a wide variety of body image was seen amongst women with mean scores of 3.30

318 [SD: 1.45] for pregnancy body image, 3.34 [SD: 1.44] for prospective postnatal body image and 2.55 [SD: 1.41] for dieting during pregnancy. Although dieting during pregnancy was lower than body image concerns, $32.5 \%$ of women $(\mathrm{N}=43)$ reported actively limiting their food intake during pregnancy to avoid gaining weight although only sixteen (12.5\%) reported they were following a diet during pregnancy.

\section{Body image and BMI}

325 Body image during pregnancy was significantly associated with pre-pregnant BMI.

326 Concerns about pregnancy body image [Pearson's $r=.352, p=.000$ ] and dieting 327 during pregnancy [Pearson's $r=.231, p=.005$ ] were both significantly associated 
with raised BMI. No significant association was found between prospective postnatal concerns and BMI. Body image concerns were not unique to those with an

330 overweight BMI however. Exploring those with a normal or underweight BMI, 56.1\%

331 had a mean score of four or over (signifying agree or strongly agree) for pregnancy

332 body image concerns, $53.0 \%$ for prospective postnatal concerns and $23.3 \%$ for

333 dieting behavior.

Weight change was also significantly associated with body image. Mothers who were significantly heavier at six months postpartum than before pregnancy had reported significantly higher pregnancy body image concerns (Pearson's $r=.156, p=$ .040 ) and dieting behavior (Pearson's $r=.155, p=.041$ ) during pregnancy. No significant association was found with postnatal concerns.

\section{Body image, BMI and breastfeeding}

Mothers reported both planned breastfeeding duration (during pregnancy) and actual breastfeeding duration (at six months postpartum).

\section{Planned duration}

Planned breastfeeding duration was not significantly associated with prenatal BMI or weight change. A MANCOVA was performed to examine differences in body image between those who planned to breast or formula feed at birth. Covariates included maternal age, education, occupation, marital status, prenatal BMI, postnatal BMI and weight change. A significant difference in pregnancy body image $[F(1,123)=$ $5.46, p=.021]$, prospective postnatal body image $[F(1,123)=12.21, p=.000]$ and dieting during pregnancy $[F(1,123)=5.67, p=.017]$ was seen. Mothers who planned to formula feed had higher body image concerns.

To examine planned breastfeeding duration, formula use from birth was recorded as

357 zero days. Using partial correlations controlling for maternal age, education, occupation, marital status and prenatal BMI, postnatal BMI and weight change, significant associations were found between planned breastfeeding duration and 
Mothers reported breastfeeding duration up to six months. Mothers were computed

pregnancy body image (Pearson's $r=-.227, p=.007$ ), prospective postnatal body image (Pearson's $r=-.380, p=.000$ ) and dieting during pregnancy (Pearson's $r=-$ $.361, p=.000)$. Mothers with higher body image concerns planned to breastfeed for a shorter duration of time or not at all.

As all three body image factors were associated with planned breastfeeding duration, a linear regression analysis using the enter method was performed to examine which factors remained predictive of planned breastfeeding duration. The model was significant, explaining $17.9 \%$ of the variance $[F(3,124=8.789, p=0.000]$. Pregnancy body image $(p=.004)$ and dieting during pregnancy $(p=.020)$ remained significant. Prospective postnatal body image was however no longer significant $(p=$ $0.90)$.

\section{Actual breastfeeding duration}

Actual breastfeeding duration was unrelated to pre-pregnant or postnatal BMI. However, mothers who breastfed at birth reported a significantly smaller weight gain compared to mothers who formula fed ( $\mathrm{t}(125)=.2 .854, \mathrm{p}=.005)$, which remained significant for any breastfeeding at two $(t(125)=3.496, p=.001)$, six (t $(125)=3.945, p=.000)$, twelve $(t(125)=3.351, p=.001)$ and twenty six weeks $(t$ $(125)=3.216, p=.001)$.

One hundred and two participants breastfed at birth (83.6\%) whilst 21 formula fed (16.4\%). A MANCOVA was performed controlling for maternal age, education, occupation, marital status and prenatal $\mathrm{BMI}$, postnatal $\mathrm{BMI}$ and weight change. Significant differences in feeding method at birth were found for body image including pregnancy body image $[F(1,123)=7.201, p=.008]$, prospective postnatal body image $[F(1,123)=17.367, p=.000]$ and dieting during pregnancy $[F(1,123)=$ 7.192, $p=.008]$. Mothers who formula fed at birth had higher body image concerns during pregnancy. 
used to examine differences in body image by breastfeeding at each of these time points (Table four). Breastfeeding at any stage was associated with significantly

394 lower body image concerns on all three factors during pregnancy.

Again, as all three body image factors were associated with actual breastfeeding duration, a further linear regression analysis was performed, including the weight change variable. The model was significant, explaining $30.0 \%$ of the variance $[F(4$, $124=8.447, p=0.000]$. Pregnancy body image $(p=.002)$, dieting during pregnancy

$400(p=.001)$, prospective body image $(p=.010)$ and weight change $(p=0.015)$ 401 remained significant.

\section{Stopping breastfeeding}

404 Participants who initiated breastfeeding at birth but stopped before six months postpartum completed a further series of questions examining why they stopped breastfeeding. Principle components analysis was performed on these items producing eight factors that explained $83.97 \%$ of the variance.

Factors were labeled 'difficult' (lack of milk, exhausting), painful (pain, infection), inconvenient (interfering with maternal lifestyle, placing greater responsibility on the

411 mother than formula feeding), body image (dislike of appearance of breasts), 412 embarrassment (did not like feeding in front of others or in public), pressure from 413 others (pressure to stop from family, partner), lack of support (poor professional 414 support) and medical reasons. Three items did not load onto any factor and were 415 excluded from the analysis (Other people made negative comments, I wasn't well 416 and I couldn't socialize).

418 Regression scores for each factor were computed and used for comparison. 419 Cronbach's alpha was also computed for each factor, ranging from 0.71 to 0.95 and 420 is also shown in Table 1.

422 Pearson's partial correlations were used to explore association between 423 breastfeeding duration and reasons for stopping (Table 5). Significant associations 
424 were found between body image during pregnancy and stopping because 425 breastfeeding was difficult or painful. Women with higher pregnancy body image 426 concerns were significantly more likely to find breastfeeding difficult or painful. 427 Additionally, significant correlations were found between prospective postnatal 428 concerns and stopping because of public feeding and body image. Women with 429 higher postnatal body image concerns were significantly more likely to stop because 430 of a dislike of public feeding and higher concerns about the impact of breastfeeding 431 on their body.

433 No significant correlations were found between reasons for stopping breastfeeding 434 and dieting.

\section{Discussion}

438 This study explores the association between maternal body image during pregnancy 439 and breastfeeding intention and duration. Although previous research has 440 highlighted the influence of maternal weight during pregnancy and specific concerns 441 related to breast appearance / identity and the postnatal period upon infant feeding, 442 little research has considered the impact of wider maternal body image. Data 443 showed that higher body image concerns were associated with both intention to use 444 and actual use of formula from birth and intended or actual shorter breastfeeding duration. Notably these concerns were not limited to women who were overweight,

446 and actual BMI was unrelated to breastfeeding initiation and duration. The findings 447 have important application for those working with women during pregnancy and the 448 postnatal period both in terms of considering the overall issue of maternal body 449 image and the impact upon breastfeeding duration.

451 The research considered three separate aspects of body image during pregnancy: 452 pregnancy body image concerns, prospective concerns for postnatal appearance and 453 dieting behavior. All three behaviors were predictive of breastfeeding intention, 454 initiation and breastfeeding duration. Higher concerns on each factor were 455 associated with intended and actual formula use from birth and decreased likelihood 
456 of planned or actual breastfeeding at two, six, twelve and twenty six weeks. Body

457 image was predictive of breastfeeding independently of wider maternal background

458 including demographic factors, birth mode and weight. The regression analysis

459 showed that all three elements remained predictive.

460

461 Previous research has shown that issues related to body image can discourage 462 women from breastfeeding. Mothers who feel embarrassed breastfeeding in public 463 (Khoury, Moazzem, Jarjoura, Carothers \& Hinton, 2005), worry about the 464 appearance of breastfeeding on their breasts (Wambach \& Cohen, 2009) or want to 465 reclaim their body for themselves (Earle, 2002) are less likely to breastfeed. Issues 466 such as leaking breasts (Lewallen et al. 2006), difficulty adapting to thinking of the 467 breast other than a sexual object (Brown, Raynor \& Lee, 2011) and conflict with a 468 partner who doesn't like her breastfeeding (Thulier \& Mercer, 2008), can all reduce 469 breastfeeding intention and duration. This study extends the research to show that 470 wider body image issues related to pregnancy and changing shape and appearance, 471 rather than those only centered around changes in breast appearance and use can 472 affect whether a mother intends to, or does, initiate or continue breastfeeding.

474 Body image during pregnancy (pregnancy, prospective postnatal and dieting during 475 pregnancy) was notably linked to both intended and actual breastfeeding duration. 476 Mothers with higher body image concern more likely to intend to use formula from 477 birth or to breastfeed for a shorter duration as well as actually do so. This suggests 478 that perceptions about breastfeeding are driving feeding choices rather than actual 479 negative experiences such as finding it embarrassing to feed in front of others. 480 Indeed, these perceptions may be preventing women from attempting to breastfeed 481 in the first place, rather than experiencing it for themselves. This fits well with 482 previous research showing that first time pregnant women hold many negative 483 perceptions about breastfeeding such as that it is embarrassing, inconvenient or 484 difficult based on information passed from friends or family (Rojjanasrirat \& Sousa, 485 2010). 
The question arises as to why body image concerns during pregnancy impact upon the intention and decision to breastfeed. It is likely that issues such as not wanting to

489 feed in public, concerns about the appearance of the breast or wanting to regain their body for themselves (Khoury et al, 2005; Wambach \& Cohen, 2009; Lewallen et al. 2006) apply to those with body dissatisfaction. However, this study looked at body image factors not specifically related to breastfeeding.

Maternal weight did not explain the relationship and was indeed included as a measure primarily to distinguish between weight and body image. It appeared that maternal thoughts and evaluations of their body shape and appearance during pregnancy were associated with breastfeeding duration rather than their weight per se. Previous research has shown that mothers who are overweight are less likely to breastfeed or to do so for only a short duration (Kitsantas \& Pawloski, 2009; Hilson, Rasmussen \& Kjolhede, 2004). However although BMI was associated with body

501 image the findings showed body dissatisfaction was not limited to overweight women, and in fact BMI was not associated with breastfeeding duration. Instead,

503 how a mother felt about her changing appearance and concerns about weight gain 504 predicted breastfeeding duration independently of her weight. However, notably, the variable of 'weight change' during pregnancy was significant. Mothers who gained the greatest amount of weight were less likely to plan or actually breastfeed. This suggests that it might be changes in body shape, appearance and image that are important rather than weight itself. Greater weight gain or retention may negatively affect body image satisfaction, in turn affecting breastfeeding duration.

511 Data regarding reasons for breastfeeding cessation might explain the findings. Body

512 image was also linked to reasons for stopping breastfeeding. Specifically two 513 patterns emerged in the data. Firstly, concerns about how her body would appear 514 postnatally were linked to stopping breastfeeding because of concerns about the 515 impact of breastfeeding on her breasts and embarrassment at feeding in front of 516 others. This fits well with previous findings that show these factors to be common 517 reasons for stopping breastfeeding (Thulier \& Mercer, 2008; Brown, Raynor \& Lee, 518 2011; Wambach \& Cohen, 2009). If a mother has higher body image concerns it is 
519 likely she is more aware of herself in front of others (Grogan, 2007). She may worry

520 that others are paying her high levels of attention, which may exacerbate anxiety

521 over public feeding. Likewise, women with negative body image are more likely to be

522 self critical and have lower self esteem (Fanzoi, Vasquez, Sparapani, Frost, Martin \&

523 Aebly, 2012) which may exacerbate how she feels about any postnatal changes to

524 her body. Mothers with eating disorders report higher levels of social anxiety and

525 self awareness (Godart, Flament, Perderau \& Jeammet, 2002).

527 However, women who held high body image concerns about their pregnancy 528 appearance during pregnancy were more likely to stop breastfeeding because they 529 found it difficult or painful. This finding is less expected and understandable than the 530 link between postnatal image and stopping for reasons of embarrassment / public 531 feeding but the pattern in factors of both difficulty and pain being significant 532 suggests an underlying contributor. It could be that body image concerns during 533 pregnancy and prospective postnatal concerns are very different issues. Pregnancy is 534 a time of expected changes in weight and appearance and women can feel liberated 535 at this time (Loth, Bauer, Wall, Berge \& Neumark-Sztainer, 2011). Indeed, many 536 women report worrying less about their appearance and choosing to relax their diet 537 at this time (Nash, 2013). Conversely, levels of postnatal body dissatisfaction are 538 very common. Women feel under increasing pressure to lose weight and regain their 539 pre pregnancy appearance (Riley, 2011). The current findings showed that although 540 pregnancy body image concerns were related to $\mathrm{BMI}$, prospective postnatal 541 concerns were not, suggesting postnatal concerns may be more common regardless 542 of weight. Additionally, in the regression analysis, prospective postnatal concerns did 543 not remain a significant predictor of breastfeeding duration implying it has a weaker 544 link with breastfeeding. Thus, although levels of body dissatisfaction during 545 pregnancy are growing (Skouteris et al, 2005), perhaps concerns at this time are 546 indicative of other issues such as anxiety or low self-esteem that may make 547 breastfeeding more difficult.

549 For example, maternal mental health may play a role. Body image dissatisfaction 550 during pregnancy has also been associated with increased risk of depression during 
551 pregnancy and the postpartum period (Downs, DiNallo \& Kirner, 2008). Postnatal

552 depression is linked to finding breastfeeding more painful and difficult (Field, 2010).

553 Moreover body image dissatisfaction has been linked to increased general anxiety

554 (Etu \& Gray, 2010). Women who are anxious about breastfeeding are more likely to

555 find it difficult, worry that their infant is not getting enough milk or to feel unable to

556 solve problems if they arise (Brown, 2013; Li et al, 2008; Sachs, Dykes \& Carter,

557 2006). Similarly, poor confidence and self-efficacy, which are significantly lower in

558 those with body dissatisfaction (Grabe \& Hyde, 2009), are linked to finding

559 breastfeeding more difficult and subsequently a shorter breastfeeding duration

560 (Forster et al, 2006; Brown, Raynor \& Lee, 2011).

561

562 Alternatively, a woman's wider personality may play a role. Introversion is associated 563 with body dissatisfaction (Swami, Hadji-Michael \& Furnham, 2008). Indeed, women

564 who are more introverted are more likely to find breastfeeding difficult (Brown, 565 2013). Perfectionist traits are also common amongst those with body image 566 concerns (Boone, Soenens \& Braet, 2011) and may lead women to find breastfeeding 567 more difficult (O'Brien, 2007). Body image concerns may also be indicative of social 568 anxiety, a disorder which is higher amongst those with body image concerns (Cash, 569 Theriault \& Annis, 2004) with anxiety known to make breastfeeding more difficult 570 (O’Brien, Buikstra \& Hegney, 2008).

572 Women may also project their own body image and weight insecurities onto their 573 infant. Research has shown that mothers with body image concerns and restrained 574 eating are more likely to try and restrict their child's intake of food (Duke, Bryson, 575 Hammer \& Agras, 2004) as early as the weaning period (Brown \& Lee, 2011). One 576 study showed that eating disordered women are more likely to try and breastfeed 577 their infant to a strict routine, becoming distressed if their infant wanted to feed 578 more frequently (Evans \& Grange, 1995). Controlling feeds during breastfeeding has 579 been associated with finding breastfeeding more difficult and breastfeeding 580 cessation (Brown, Raynor \& Lee, 2011b). 
582 Finally, experience of motherhood and perceptions of infant temperament may play

583 a role. Motherhood is a huge change to a woman's life and one where her time is

584 largely controlled by the infant. If a woman is used to being quite controlling with 585 herself and her body, she may struggle with an infant who appears not to follow set 586 routines. Mothers who want a strict routine for their infant are more likely to 587 formula feed as it allows greater maternal control (Brown \& Lee, 2012). Linked to 588 this, mothers may view their infant temperament differently. Mothers who are 589 anxious (Austin, Hadzi-Pavlovic, Leader, Saint \& Parker, 2005), depressed (McGratj, 590 Records \& Rice, 2008) or lacking in self efficacy (Anzman-Frasca, Stifter, Paul \& Birch, 591 2013) are more likely to perceive their infants to be difficult, as are women with 592 eating disoders (Zerwas, Von Holle Torgesen, Reichborn-Kjennerud, Stoltenberg \& 593 Bulik, 2012). Mothers who perceive their infants to have a difficult temperament are 594 more likely to report feeding difficulties (Farrow \& Blissett, 2006), introduce formula 595 (Niegel, Ystrom, Hagtvet \& Vollrath, 2008) and start complementary feeding before 596 six months to soothe their infant (Wasser et al, 2011).

598 These possible explanations are however speculative. Further research is needed to 599 examine the wider factors that might moderate the relationship between pregnancy 600 body dissatisfaction and breastfeeding and how the role of weight gain influences 601 this. However the findings have important implications for those working to support 602 pregnant women and new mothers. Two main issues arise from the data; body 603 image concerns during pregnancy amongst normal weight women and the impact 604 upon breastfeeding duration. Appropriate levels of weight gain and body changes 605 during pregnancy are considered to be healthy and important aspects of 606 pregnancy. The risk arises that women who become concerned about their 607 changing appearance may try and limit weight gain which can increase the risk of 608 low birth weight and preterm birth (Viswathan et al, 2008; Kothari, Wendt, Liggins, 609 Overton, \& Carmen Sweezy, 2011). Although interventions to prevent excessive 610 weight gain during pregnancy are growing, there may be women at risk of not 611 gaining enough weight. 
613 Midwives are already encouraged to talk about healthy eating and weight gain from

614 an obesity perspective due to known links with infant macrosomia, caesarean

615 section and later childhood overweight (Amorim, Rossner, Neovius, Lourenco, \& 616 Linne, 2007; Olson, 2008; Siega-Riz et al., 2009; Olson, Strawderman, \& Dennison,

617 2009). However, body image is not routinely considered in antenatal care (Leddy, 618 Jones, Morgan \& Schulkin, 2009). Current UK clinical recommendations advise 619 against routine repeated weighing of women during pregnancy (NICE, 2008; NICE, 620 2010). These findings support this stance, suggesting that drawing attention to a 621 woman's changing shape in a negative way might increase body image 622 dissatisfaction and impact upon, amongst other things, breastfeeding duration. The 623 findings that weight change, rather than BMI itself, are also linked to breastfeeding 624 duration further support this, suggesting that women with a healthy BMI but poor 625 body image satisfaction may be overly concerned about their weight and 626 appearance. Although weight gain restriction may be safe amongst overweight and 627 obese pregnant women (Claesson, Brynhildsen, Cedergren, Jeppsson, Sydsjo \& 628 Josefsson, 2009), too little weight gain during pregnancy has been associated with 629 risk of low birth weight and preterm birth (Viswathan et al, 2008; Kothari, Wendt, 630 Liggins, Overton, \& Carmen Sweezy, 2011). Talking positively and realistically to 631 women about their changing shape, the importance of healthy weight gain and 632 concepts of sensible weight loss after the birth may be more productive.

634 Secondly, the link between body image and breastfeeding is important. Women 635 who feel uncomfortable about their changing shape, who try to limit weight gain or 636 who have concerns about the appearance of their body after pregnancy may be less 637 likely to breastfeed, or struggle to do so if they initiate. Discussion during pregnancy 638 about how they feel about their changing shape and function of their breasts 639 (outside of simple weight gain) and issues such as feeding in public feeding and 640 considering strategies to overcome such issues may encourage or enable further 641 breastfeeding.

643 The research does have its limitations. The sample size was relatively small and self 644 selecting. Although a wide range of participants did take part, mothers were older 
645 and more educated than average. Also, although levels of breastfeeding initiation 646 were similar to population norms, a higher proportion of mothers breastfed for at 647 least six months (ref). Care should be taken in generalizing the findings to a wider 648 population. Further research should explore the issue in a wider population based 649 sample.

650 In addition, online adverts were utilized as part of the recruitment process. This may 651 be criticized for increasing sample bias; internet users may be a well educated and 652 proactive group (Drentea \& Moren-Cross 2005). However internet recruitment is 653 growing in popularity in health research (e.g. Alcade \& Cristina, 2011; Hamilton, 654 White \& Cuddihy, 2012; Ferguson \& Hansen, 2012) as it allows access to a targeted 655 sample in a cheap and effective way (Koo \& Skinner, 2005). It is particularly useful in 656 recruiting pregnant and new mothers due to high use of internet forums amongst 657 this sample (Hall \& Irvine 2008, Plantin \& Daneback 2009). Such forums are now 658 typically used by a wide spread of demographic groups (Sarkadi \& Bremberg 2005; 659 Quan-Haase et al. 2002).

660 Thirdly, the study used a body image questionnaire developed for the purpose of the 661 study. This could be criticized for lacking validity. However, although a number of 662 validated questionnaires exist for examining body image, these have had limited use 663 amongst pregnant samples. Data suggests that using measures intended for non 664 pregnant women may be inaccurate and prone to bias (Fuller-Tyszkiewicz, Skouteris, 665 Watson \& Hill, 2012). In addition, these questionnaires did not explore the specific 666 issues of body image that arise during pregnancy such as changing shape, 667 appearance of breasts and stretch marks. Items were based on existing literature 668 examining body image during pregnancy and that of factors affecting breastfeeding 669 duration (Thulier \& Mercer, 2008; Lie et al, 2009; Brown et al, 2011). Finally, factor 670 analysis was used to group items, producing logical factor groupings and Cronbach's 671 alpha showed good validity.

672 In conclusion, higher body image concerns during pregnancy were associated with 673 formula use from birth or shorter breastfeeding duration. Weight gain during 674 pregnancy may play an important role in this. Issues with embarrassment, changing 
675 appearance of breasts and finding breastfeeding more difficult were more common 676 amongst those with higher body image concerns. The findings are important to 677 those working with women both during pregnancy and in the postpartum period to 678 understanding the impact of body image upon intention and ability to initiate and 679 continue breastfeeding.

680 
Alexander, A., Dowling, D., \& Furman, L. (2010). What do pregnant low-income women say about breastfeeding?. Breastfeeding Medicine, 5(1), 17-23.

Amorim, A. R., Rossner, S., Neovius, M., Lourenco, P. M., \& Linne, Y. (2007). Does excess pregnancy weight gain constitute a major risk for increasing long-term BMI? Obesity, 15(5), 1278-1286.

Angell, C. (2013). Bare necessities: why does society make breastfeeding so complicated?. The practising midwife, 16(3), 5-5.

Anzman-Frasca, S., Stifter, C. A., Paul, I. M., \& Birch, L. L. (2013). Infant temperament and maternal parenting self-efficacy predict child weight outcomes. Infant Behavior and Development, 36(4), 494-497.

Austin, M. P., Hadzi-Pavlovic, D., Leader, L., Saint, K., \& Parker, G. (2005). Maternal trait anxiety, depression and life event stress in pregnancy: relationships with infant temperament. Early human development, 81(2), 183-190.

Barnes J, Stein A, Smith T, Pollock JI, ALSPAC Study Team: Extreme attitudes to body shape, social and psychological factors and a reluctance to breast feed. $J$ R Soc Med 1997, 90:551559.

Barnes J, Stein A, Smith T, Pollock Jl. Extreme attitudes to body shape, social and psychological factors and a reluctance to breast feed. ALSPAC study team. Avon longitudinal study of pregnancy and childhood. Journal of the Royal Society of Medicine. 1997;90:551559.

Boone, L., Soenens, B., \& Braet, C. (2011). Perfectionism, body dissatisfaction, and bulimic symptoms: The intervening role of perceived pressure to be thin and thin ideal internalization. Journal of Social and Clinical Psychology, 30(10), 1043-1068.

Brouwer, M. A., Drummond, C., \& Willis, E. (2012). Using Goffman's theories of social 
interaction to reflect first-time mothers' experiences with the social norms of infant feeding. Qualitative Health Research, 22(10), 1345-1354.

Brown, A., \& Lee, M. (2011). Maternal child-feeding style during the weaning period: association with infant weight and maternal eating style. Eating behaviors, 12(2), 108-11

Brown, A., Raynor, P., \& Lee, M. (2011a). Healthcare professionals' and mothers' perceptions of factors that influence decisions to breastfeed or formula feed infants: a comparative study. Journal of advanced nursing, 67(9), 1993-2003.

Brown, A., Raynor, P., \& Lee, M. (2011b). Maternal control of child-feeding during breast and formula feeding in the first 6 months post-partum. Journal of Human Nutrition and Dietetics, 24(2), 177-186.

Bulik CM, Sullivan PF, Fear JL, Pickering A, Dawn A, McCullin M. Fertility and reproduction in women with anorexia nervosa: a controlled study. The Journal of Clinical Psychiatry. 1999;60:130-137.

Cash TF, Fleming EC, Alindogan J, Steadman L, Whitehead A: Beyond body image as a trait: the development and validation of the Body Image States Scale. Eat Disord 2002, 10:103113.

CLAESSON, I., Brynhildsen, J., Cedergren, M., Jeppsson, A., Sydsjö, A., \& Josefsson, A. (2009). Weight gain restriction during pregnancy is safe for both the mother and neonate. Acta obstetricia et gynecologica Scandinavica, 88(10), 1158-1162.

Clark A, Skouteris H, Wertheim EH, Paxton SJ, Milgrom J: The relationship between depression and body dissatisfaction across pregnancy and the postpartum: A prospective study. J Health Psychol 2009, 14(1):27-35.

Conrad, R., Schablewski, J., Schilling, G., \& Liedtke, R. (2003). Worsening of symptoms of Bulimia Nervosa during pregnancy. Psychosomatics, 44(1), 76-78. doi: 10.1176/appi.psy.44.1.76

Conti J, Abraham S, Taylor A. Eating behaviour and pregnancy outcome. Journal of 
Psychosomatic Research. 1998;44:465-477.

Conway, R., Reddy, S., \& Davies, J. (1999). Dietary restraint and weight gain during pregnancy. European Journal of Clinical Nutrition, 53, 849-853. doi: 10.1038/sj.ejcn.1600864

Devine, C. M., Bove, C. F., \& Olson, C. M. (2000). Continuity and change in women's weight orientations and lifestyle practices through pregnancy and the postpartum period: The influence of life course trajectories and transitional events. Social Science \& Medicine, 50, 567-582.

Downs, D. S., DiNallo, J. M., \& Kirner, T. L. (2008). Determinants of pregnancy and postpartum depression: prospective influences of depressive symptoms, body image satisfaction, and exercise behavior. Annals of Behavioral Medicine, 36(1), 54-63.

Duncombe D, Wertheim EH, Skouteris H, Paxton SJ, Kelly L: How well do women adapt to changes in their body size and shape across the course of pregnancy? J Health Psychol 2008, 13(4):503-515.

Duncombe D, Wertheim EH, Skouteris H, Paxton SJ, Kelly L. How well do women adapt to changes in their body size and shape across the course of pregnancy? Journal of Health Psychology. 2008;13:503-515.

Duncombe, D., Wertheim, E. H., Skouteris, H., Paxton, S. J., \& Kelly, L. (2008). How well do women adapt to changes in their body size and shape across the course of pregnancy? Journal of Health Psychology, 13(4), 503-515.

Dyson, L., Green, J. M., Renfrew, M. J., McMillan, B., \& Woolridge, M. (2010). Factors influencing the infant feeding decision for socioeconomically deprived pregnant teenagers: the moral dimension. Birth, 37(2), 141-149

Etu, S. F., \& Gray, J. J. (2010). A preliminary investigation of the relationship between induced rumination and state body image dissatisfaction and anxiety. Body image, 7(1), 8285. 

Factor analysis of the Body-Self Relations Questionnaire. Journal of personality assessment, 55(1-2), 135-144.

Cash, T. F., Thériault, J., \& Annis, N. M. (2004). Body image in an interpersonal context: Adult attachment, fear of intimacy and social anxiety. Journal of Social and Clinical Psychology, 23(1), 89-103.

690

691 Cooper, P. J., Taylor, M. J., Cooper, Z., \& Fairbum, C. G. (1987). The development and 692 validation of the Body Shape Questionnaire. International Journal of eating 693 disorders, 6(4), 485-494.

Evans J, Le Grange D. Body size and parenting in eating disorders: a comparative study of the attitudes of mothers toward their children. Int J Eat Disord. 1995;18:3948. and infant temperament as predictors of early infant feeding problems: A longitudinal study. International Journal of Eating Disorders, 39(2), 128-134.

Field, T. (2010). Postpartum depression effects on early interactions, parenting, and safety practices: A review. Infant Behavior and Development, 33(1), 1-6.

705 Foster SF, Slade P, Wilson K. Body image, maternal fetal attachment, and breast 706 feeding. Journal of Psychosomatic Research. 1996;41:181-184

707 Franko, D. L. (2006). Eating disorders in pregnancy and the postpartum: Empirically 708 informed treatment guidelines. In V. Hendrick (Ed.), Psychiatric disorders in 709 pregnancy and the postpartum: Principles and treatment (pp. 179-196). Totowa, NJ: 710 Humana Press. 
711 Franzoi, S. L., \& Shields, S. A. (1984). The Body Esteem Scale: Multidimensional

712 structure and sex differences in a college population. Journal of personality 713 assessment, 48(2), 173-178.

714 Franzoi, S. L., Vasquez, K., Sparapani, E., Frost, K., Martin, J., \& Aebly, M. (2012).

715 Exploring Body Comparison Tendencies Women Are Self-Critical Whereas Men Are

716 Self-Hopeful. Psychology of Women Quarterly, 36(1), 99-109.

717

718 Frederick DA, Forbes GB, Grigorian K, Jarcho JM: The UCLA Body Project I: Gender 719 and ethnic differences in self-objectification and body satisfaction among 2,206 720 undergraduates. Sex Roles 2007, 57:317-327.

721 Frederick DA, Peplau LA, Lever J: The swimsuit issue: Correlates of body image in a 722 sample of 52,677 heterosexual adults. Body Image 2006, 4:413-419.

723 Fuller-Tyszkiewicz, M., Skouteris, H., Watson, B., \& Hill, B. (2012). Body image during 724 pregnancy: an evaluation of the suitability of the body attitudes questionnaire. $B M C$ 725 pregnancy and childbirth, 12(1), 91.

726 Galler, J. R., Harrison, R. H., Ramsey, F., Butler, S., \& Forde, V. (2004).

727 Postpartummaternal mood, feeding practices, and infant temperament in Barbados.

728 Infant Behavior \& Development, 27(3), 267-287

729 Goodwin A, Astbury J, McMekken J. Body image and psychological well-being in 730 pregnancy: A comparison of exercisers and non-exercisers. Australian and New 731 Zealand Journal of Obstetrics and Gynaecology. 2000;40:443-447.

733 Grabe, S., \& Hyde, J. S. (2009). Body objectification, MTV, and psychological 734 outcomes among female Adolescents1. Journal of Applied Social Psychology, 39(12), 735 2840-2858.

737 Grogan, S. (2007). Body image: Understanding body dissatisfaction in men, women 738 and children. Routledge. 
739 Hauff, L. E. and Demerath, E. W. (2012), Body image concerns and reduced

740 breastfeeding duration in primiparous overweight and obese women. Am. J. Hum.

741 Biol., 24: 339-349. doi: 10.1002/ajhb.22238

742

743 Haughton, J., Gregorio, D., \& Pérez-Escamilla, R. (2010). Factors associated with 744 breastfeeding duration among Connecticut special supplemental nutrition program 745 for Women, Infants, and Children (WIC) participants. Journal of Human Lactation, 746 26(3), 266-273.

747 Hedderson, M. M., Gunderson, E. P., \& Ferrara, A. (2010). Gestational weight gain 748 and risk of gestational diabetes mellitus. Obstetrics \& Gynecology, 115(3), 597-604.

749 Herman, P., \& Polivy, J. (1991). Fat is a psychological issue. New Scientist, 132, 35-39.

750 Herzog, D. B. (2001). Pregnancy complications and neonatal outcomes in women 751 with eating disorders. American Journal of Psychiatry, 158(9), 1461-1466.

752 Huang HC, Wang SY, Chen CH. Body image, maternal-fetal attachment, and choice of 753 infant feeding method: A study in Taiwan. Birth. 2004;31:183-188

754 Kaiser, L. (2002). Position of the American Dietetic Association: Nutrition and lifestyle 755 for a healthy pregnancy outcome. Journal of the American Dietetic Association, 756 102(10), 1479-1490.

757 Kothari, C. L., Wendt, A., Liggins, O., Overton, J., \& Carmen Sweezy, L. (2011). 758 Assessing maternal risk for fetal-infant mortality: A population-based study to 759 prioritize risk reduction in a Healthy Start community. Maternal and Child Health 760 Journal, 15(1), 68-76.

761 Kramer, M. S. (2003). The epidemiology of adverse pregnancy outcomes: An 762 overview. The Journal of Nutrition, 133(5), 1592S-1596S.

763 Kukla R. (2006) Ethics and ideology in breastfeeding advocacy campaigns. Hypatia, 764 Larsson G, Andersson-Ellstrom A. Experiences of pregnancy-related body shape 765 changes and of breast-feeding in women with a history of eating disorders. Eur Eat 
Loth, K. A., Bauer, K. W., Wall, M., Berge, J., \& Neumark-Sztainer, D. (2011). Body satisfaction during pregnancy. Body image, 8(3), 297-300.

Matz PE, Foster GD, Faith MS, Wadden TA: Correlates of body image dissatisfaction 70(4):1040-1044. temperament characteristics. Infant Behavior and Development, 31(1), 71-80. restraint and gestational weight gain. Journal of the American Dietetic Association, 108(10), 1646-1653

Nash, M. B. (2013). Indulgence versus restraint: A discussion of embodied eating practices of pregnant Australian women. Journal of Sociology, 1-14. routine care for the healthy pregnant woman. Clinical Guidance CG62, London. management in pregnancy and after childbirth: Public Health Guidance. London

789 Niegel, S., Ystrom, E., Hagtvet, K. A., \& Vollrath, M. E. (2008). Difficult temperament, 790 breastfeeding, and their mutual prospective effects: the Norwegian Mother and 791 Child Cohort Study. Journal of Developmental \& Behavioral Pediatrics, 29(6), 458792462. 
794 Nohr EA, Vaeth M, Baker JL, Sorensen T, Olsen J, Rasmussen KM. Combined 795 associations of prepregnancy body mass index and gestational weight gain with the 796 outcome of pregnancy. American Journal of Clinical Nutrition. 2008;87(6):17507971759.

798

799 O'Brien, M. (2007). I think I can: exploring the influence of psychological factors on 800 breastfeeding duration (Doctoral dissertation, University of Southern Queensland).

801

802 O'Brien, M., Buikstra, E., \& Hegney, D. (2008). The influence of psychological factors 803 on breastfeeding duration. Journal of Advanced Nursing, 63(4), 397-408.

804

805 Ogbuanu, C. A., Probst, J., Laditka, S. B., Liu, J., Baek, J., \& Glover, S. (2009). Reasons 806 why women do not initiate breastfeeding: A southeastern state study. Women's 807 Health Issues, 19(4), 268-278.

808 Ogbuanu, C. A., Probst, J., Laditka, S. B., Liu, J., Baek, J., \& Glover, S. (2009). Reasons 809 why women do not initiate breastfeeding: A southeastern state study. Women's $810 \quad$ Health Issues, 19(4), 268-278.

811 Olafsdottir, A. S., Skuladottir, G. V., Thorsdottir, I., Hauksson, A., \& Steingrimsdottir, 812 L. (2006). Maternal diet in early and late pregnancy in relation to weight gain. 813 International Journal of Obesity, 30(3), 492-499.

814 Olson, C. M. (2008). Achieving a Healthy Weight Gain During Pregnancy. Annual 815 Review of Nutrition, 28(1), 411-423.

816 Olson, C. M., \& Strawderman, M. S. (2003). Modifiable behavioral factors in a 817 biopsychosocial model predict inadequate and excessive gestational weight 818 gain.Journal of the American Dietetic Association, 103(1), 48-54.

819 Riley, H. (2011), Weight management before, during and after pregnancy - what are 820 the 'rules'?. Nutrition Bulletin, 36: 212-215. doi: 10.1111/j.1467-3010.2011.01891.x 
821 Rojjanasrirat, W., \& Sousa, V. D. (2010). Perceptions of breastfeeding and planned 822 return to work or school among low-income pregnant women in the USA. Journal of

823 Clinical Nursing, 19(13-14), 2014-2022.

824

Rooney BL, Schauberger CW, Mathiason MA. Impact of perinatal weight change on

826 long-term obesity and obesity-related illnesses. Obstetrics and Gynecology. $8272005 ; 106(6): 1349-1356$.

828

829 Rooney BL. Schauberger CW. Rooney BL, et al. Excess pregnancy weight gain and 830 long-term obesity: One decade later. Obstet Gynecol. 2002;100:245-252.

831

832 Siega-Riz, A. M., Herrmann, T. S., Savitz, D. A., \& Thorp, J. M. (2001). Frequency of 833 eating during pregnancy and its effect on preterm delivery. American Journal of 834 Epidemiology, 153, 647-652. doi: 10.1093/aje/153.7.647

835 Siega-Riz, A. M., Viswanathan, M., Moos, M., Deierlein, A., Mumford, S., Knaack, J., . . 836 . Lohr, K. N. (2009). A systematic review of outcomes of maternal weight gain 837 according to the Institute of Medicine recommendations: Birthweight, fetal growth, 838 and postpartum weight retention. American Journal of Obstetrics and Gynecology, 839 201(4), 339e331-314.

840 Skouteris H: Body image issues in obstetrics and gynecology. In Body image: A 841 handbook of science, practice, and prevention. 2nd edition. Edited by Cash T, Smolak 842 L. New York: Guilford Press; 2011:342-349.

843 Skouteris, H., Carr, R., Wertheim, E., Paxton, S., \& Duncombe, D. (2005). A 844 prospective study of factors that lead to body dissatisfaction during pregnancy. Body 845 Image, 2(4), 347-361. doi: 10.1016/j.bodyim.2005.09.002

846 Stapleton, H., Fielder, A. and Kirkham, M. (2008), Breast or bottle? Eating disordered 847 childbearing women and infant-feeding decisions. Maternal \& Child Nutrition, 848 4: 106-120 
849 Swami, V., Hadji-Michael, M., \& Furnham, A. (2008). Personality and individual

850 difference correlates of positive body image. Body image, 5(3), 322-325.

852 Swann, R. A., Von Holle, A., Torgersen, L., Gendall, K., Reichborn-Kjennerud, T., \&

853 Bulik, C. M. (2009). Attitudes toward weight gain during pregnancy: Results from the 854 Norwegian mother and child cohort study (MoBa). International Journal of Eating 855 Disorders, 42(5), 394-401.

856 Symons Downs, D., DiNallo, J. M., \& Kirner, T. L. (2008). Determinants of pregnancy 857 and postpartum depression: Prospective influences of depressive symptoms, body 858 image satisfaction, and exercise behavior. Annals of Behavioral Medicine, 36(1), 54859 63.

860 Thompson JK, Heinberg LJ, Altabe M, Tantleff-Dunn S: An introduction to the 861 concept of body image disturbance: History, definitions, and descriptions. In Exacting 862 beauty: Theory, assessment, and treatment of body image disturbance. Edited by 863 Thompson J, Heinberg L, Altabe M, Tantleff- Dunn S. Washington: American 864 Psychological Association; 1999:3-15.

865 Torgersen L, Ystrom E, Haugen M, et al. Breastfeeding practice in mothers with 866 eating disorders. Matern Child Nutr. 2010;6(3):243-252.

868 Viswanathan M, Siega-Riz AM, Moos M, Deierlein A, Mumford S, Knaack J, et al. 869 Evidence report/technology assessment. Agency for Healthcare Research and 870 Quality; 2008. Outcomes of maternal weight gain. Report No.: 168.

872 Wambach, K. A., \& Cohen, S. M. (2009). Breastfeeding experiences of urban adolescent mothers. Journal of pediatric nursing, 24(4), 244-254.

874 Wasser, H., Bentley, M., Borja, J., Goldman, B. D., Thompson, A., Slining, M., \& Adair, 875 L. (2011). Infants perceived as "fussy" are more likely to receive complementary 876 foods before 4 months. Pediatrics, 127(2), 229-237.

878 Webb, J. B., Siega-Riz, A. M., \& Dole, N. (2008). Psychosocial determinants of 
879 adequacy of gestational weight gain. Obesity, 17, 300-309.

880 Zerwas, S., Von Holle, A., Torgersen, L., Reichborn-Kjennerud, T., Stoltenberg, C., \& 881 Bulik, C. M. (2012). Maternal eating disorders and infant temperament: Findings 882 from the norwegian mother and child cohort study. International Journal of Eating 883 Disorders, 45(4), 546-555

884 


\begin{tabular}{|c|c|c|c|}
\hline & $\begin{array}{l}\text { Pregnancy } \\
\text { body } \\
\text { image }\end{array}$ & $\begin{array}{c}\text { Prospective } \\
\text { postnatal } \\
\text { body image }\end{array}$ & $\begin{array}{l}\text { Dieting } \\
\text { during } \\
\text { pregnancy }\end{array}$ \\
\hline Pregnancy makes me feel less attractive & .408 & & \\
\hline $\begin{array}{l}\text { I worry that my partner finds me unattractive during } \\
\text { pregnancy }\end{array}$ & .790 & & \\
\hline $\begin{array}{l}\text { I am worried about the effect of pregnancy on the } \\
\text { appearance of my breasts }\end{array}$ & .588 & & \\
\hline I compare my body negatively to other pregnant women & .603 & & \\
\hline I feel that I am gaining/or have gained too much weight & .588 & & \\
\hline I worry about losing the weight after pregnancy & .470 & & \\
\hline I worry about stretch marks & .727 & .780 & \\
\hline I worry what my body will look like after pregnancy & & .796 & \\
\hline $\begin{array}{l}\text { I worry that my partner will find me unattractive after } \\
\text { pregnancy }\end{array}$ & & .782 & \\
\hline I worry what my breasts will look like after pregnancy & & .725 & \\
\hline $\begin{array}{l}\text { I have dieted during pregnancy to avoid gaining too } \\
\text { much weight }\end{array}$ & & & .800 \\
\hline I have tried to limit my weight gain during pregnancy & & & .758 \\
\hline $\begin{array}{l}\text { Other peoples comments about my pregnant body have } \\
\text { upset me }\end{array}$ & & & .696 \\
\hline$\%$ of variance explained & 35.840 & 11.640 & 10.594 \\
\hline Cronbach's alpha & .729 & .781 & .782 \\
\hline
\end{tabular}




\begin{tabular}{|c|c|c|c|c|c|c|c|c|}
\hline & 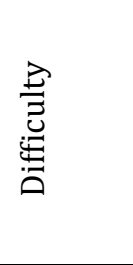 & 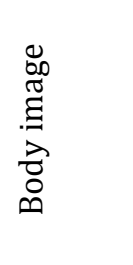 & 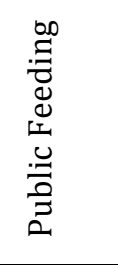 & 气 & 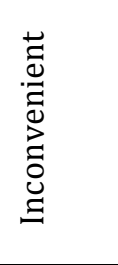 & 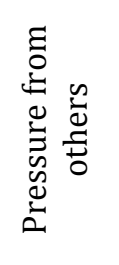 & 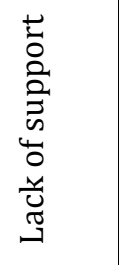 & 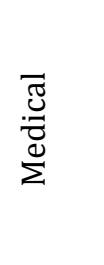 \\
\hline $\begin{array}{l}\text { The baby wouldn't latch on properly } \\
\text { The baby was feeding all the time } \\
\text { My baby wasn't gaining enough weight } \\
\text { I didn't have enough milk } \\
\text { Baby didn't want to breastfeed anymore } \\
\text { I was exhausted }\end{array}$ & $\begin{array}{l}.703 \\
.826 \\
.757 \\
.618 \\
.617 \\
.722 \\
\end{array}$ & & & & & & & \\
\hline $\begin{array}{l}\text { Breastfeeding was ruining my breasts } \\
\text { I felt unattractive } \\
\text { My breasts kept leaking } \\
\text { I wanted my body back for me }\end{array}$ & & $\begin{array}{l}.419 \\
.804 \\
.784 \\
.830 \\
\end{array}$ & & & & & & \\
\hline $\begin{array}{l}\text { I didn't like feeding in public } \\
\text { I didn't like feeding in front of others } \\
\text { I was stuck in the house breast feeding }\end{array}$ & & & $\begin{array}{l}.866 \\
.910 \\
.674\end{array}$ & & & & & \\
\hline $\begin{array}{l}\text { It was too painful } \\
\text { My nipples were cracked } \\
\text { I got mastitis, thrush or another problem } \\
\text { It was too difficult }\end{array}$ & & & & $\begin{array}{l}.853 \\
.712 \\
.747 \\
.730 \\
\end{array}$ & & & & \\
\hline $\begin{array}{l}\text { I never knew when the baby was going to } \\
\text { feed } \\
\text { I didn't like being responsible for all the } \\
\text { feeds } \\
\text { I couldn't keep track of milk intake } \\
\text { I couldn't leave the baby } \\
\text { I wanted a more predictable routine }\end{array}$ & & & & & $\begin{array}{l}.809 \\
.604 \\
.760 \\
.458 \\
.633 \\
\end{array}$ & & & \\
\hline $\begin{array}{l}\text { My partner wanted me to stop } \\
\text { My mother wanted me to stop } \\
\text { Friends wanted me to stop } \\
\text { I didn't know anyone else who breastfed } \\
\text { Other people felt excluded }\end{array}$ & & & & & & $\begin{array}{l}.671 \\
.695 \\
.639 \\
.652 \\
.633\end{array}$ & & \\
\hline $\begin{array}{l}\text { I couldn't get any help with problems } \\
\text { I didn't have enough support } \\
\text { I couldn't get any professional advice }\end{array}$ & & & & & & & $\begin{array}{l}.788 \\
.631 \\
.821 \\
\end{array}$ & \\
\hline $\begin{array}{l}\text { The baby wasn't well } \\
\text { I was taking medication } \\
\text { A health professional advised me to stop } \\
\text { I couldn't breastfeed }\end{array}$ & & & & & & & & $\begin{array}{l}.824 \\
.844 \\
.821 \\
.847 \\
\end{array}$ \\
\hline Percentage of variance explained & 36.975 & 11.035 & 7.783 & 7.341 & 5.579 & 5.075 & 5.320 & 4.818 \\
\hline Cronbach's alpha & .705 & .784 & .906 & .770 & .869 & .923 & .892 & .849 \\
\hline
\end{tabular}

891 Table one shows regression scores for each item and how they load onto each factor produced.

892 Items in bold signify items which group strongly on each factor

893

894 
Table three. Sample distribution by Demographic Factors

\begin{tabular}{|l|l|rr|}
\hline Indicator & Group & $\mathbf{~ N}$ & $\mathbf{\%}$ \\
\hline Age & $\leq 19$ & 4 & 3.1 \\
& $20-24$ & 21 & 16.4 \\
& $25-29$ & 25 & 19.5 \\
& $30-34$ & 52 & 40.6 \\
& $35 \geq$ & 26 & 20.3 \\
\hline \multirow{4}{*}{ Education } & School & 30 & 23.4 \\
& College & 27 & 21.1 \\
& Higher & 48 & 32.8 \\
& Postgraduate & 29 & 22.7 \\
\hline Marital Status & Married & 89 & 69.5 \\
& Cohabiting & 27 & 21.1 \\
& Partner & 9 & 7.0 \\
& Single & 3 & 2.3 \\
\hline Maternal & Professional \& managerial & 69 & 53.9 \\
occupation & Skilled & 23 & 18.0 \\
& Unskilled & 16 & 12.5 \\
\hline
\end{tabular}

896

897

898

899 
901 Table Four: Differences in pregnancy body image by infant feeding group at two, 902 six, twelve and twenty six weeks postpartum

903

904

\begin{tabular}{|c|c|c|c|c|c|}
\hline Time point & $\begin{array}{l}\text { Breast } \\
\text { (N) }\end{array}$ & $\begin{array}{l}\text { Formula } \\
\qquad \text { (N) }\end{array}$ & $\begin{array}{l}\text { Pregnancy body } \\
\text { image }\end{array}$ & $\begin{array}{l}\text { Prospective } \\
\text { postnatal body } \\
\text { image }\end{array}$ & $\begin{array}{l}\text { Dieting during } \\
\text { pregnancy }\end{array}$ \\
\hline Two weeks & 102 & 26 & $\begin{array}{l}F(1,124)=7.92, p \\
=.006\end{array}$ & $\begin{array}{l}F(1,124)=10.68 \\
p=.001\end{array}$ & $\begin{array}{l}F(1,124)=7.90 \\
p=.006\end{array}$ \\
\hline Six weeks & 87 & 41 & $\begin{array}{l}F(1,124)=4.03, p \\
=.046\end{array}$ & $\begin{array}{l}F(1,124)=18.17 \\
p=.000\end{array}$ & $\begin{array}{l}F(1,124)=21.67 \\
p=.000\end{array}$ \\
\hline $\begin{array}{l}\text { Twelve } \\
\text { weeks }\end{array}$ & 62 & 66 & $\begin{array}{l}F(1,124)=4.10, p \\
=.045\end{array}$ & $\begin{array}{l}F(1,124)=11.30 \\
p=.001\end{array}$ & $\begin{array}{l}F(1,124)=15.98 \\
p=.000\end{array}$ \\
\hline $\begin{array}{l}\text { Twenty six } \\
\text { weeks }\end{array}$ & 48 & 80 & $\begin{array}{l}F(1,124)=7.51, p \\
=.007\end{array}$ & $\begin{array}{l}F(1,124)=26.31, \\
p=.000\end{array}$ & $\begin{array}{l}F(1,124)=24.99 \\
p=.000\end{array}$ \\
\hline
\end{tabular}

905 


\begin{tabular}{|l|c|c|c|}
\hline & $\begin{array}{c}\text { Pregnancy body } \\
\text { image }\end{array}$ & $\begin{array}{c}\text { Prospective } \\
\text { postnatal concerns }\end{array}$ & $\begin{array}{c}\text { Dieting during } \\
\text { pregnancy }\end{array}$ \\
\hline Difficulty & $.323(.017)^{*}$ & $-.157(.158)$ & $.088(.287)$ \\
\hline Pain & $.292(.029)^{*}$ & $-.008(.480)$ & $-.089(.286)$ \\
\hline Body Image & $.001(.499)$ & $.602(.000)^{* *}$ & $.122(.218)$ \\
\hline Public Feeding & $-.088(.287)$ & $.345(.012)^{*}$ & $.046(.385)$ \\
\hline Inconvenient & $.083(.299)$ & $.159(.154)$ & $.025(.437)$ \\
\hline $\begin{array}{l}\text { Pressure from } \\
\text { others }\end{array}$ & $.105(.252)$ & $-.073(.320)$ & $-.016(.460)$ \\
\hline Lack of support & $.137(.191)$ & $.024(.439)$ & $-.028(.428)$ \\
\hline Medical & $-.198(.101)$ & $-.193(.107)$ & $-.165(.145)$ \\
\hline
\end{tabular}
breastfeeding 
